\title{
A Study on Outcome of Adult Acute Intestinal Obstruction in a Tertiary care Hospital of Kerala
}

\author{
Asha Jose V. ${ }^{1}$ \\ ${ }^{1}$ Department of General Surgery, Malabar Medical College, Modakkalloor, Kozhikode, Kerala, India.
}

\section{ABSTRACT}

\section{BACKGROUND}

The commonest surgical emergency worldwide in adults is Acute intestinal obstruction. The commonest aetiology was found to be different in India and the western world and middle east. In the former it was obstructed inguinal hernia and in the later it was adhesions. Among the different diagnostic modalities radiology was accurate in $60 \%$ of the patients. Demography reeled different aetiological factors and diagnostic methods adopted.

Aims and Objectives of the Study- To elaborate the demography, clinical features, diagnosis and final outcome in the Adult intestinal obstruction.

\section{METHODS}

57 patients who underwent exploratory laparotomy for Adult acute intestinal obstruction (AAIO) were studied for their demography, clinical presentation, diagnostic methods adopted and operative findings were noted. The final outcome in the management of AAIO were elaborated.

\section{RESULTS}

The mean age of the patients was $47.30 \pm 6.74$ years with the youngest patient aged 36 years and the eldest was aged 54 years. Adhesions was the commonest cause for intestinal obstruction in 25 / 57 (43.85 \%) obstructed inguinal hernia in 19 / 57 (33.33\%) patients and tumours in $09 / 57$ (15.78\%) patients. The mortality rate was $19.29 \%(11 / 57)$ and the complication rate was $35.08 \%$ (20 / 57). Radiological diagnosis was accurate in $26.31 \%$ (15 / 57) of the patients.

\section{CONCLUSIONS}

The major aetiological agent was adhesions in the Adult Acute Intestinal obstruction followed by obstructed inguinal hernias and tumours. The change in the causative factor similar to the western literature was observed. CT abdomen must always be chosen as first choice for diagnosing AAIO before undertaking the surgery. Presence of strangulated bowel during surgery had grave mortality ( $p$ value - 0.001). Presence of shock was another factor contributing to the mortality ( $p$ - value 0.021).

\section{KEY WORDS}

Intestine, Obstruction, CT Scan Abdomen, and Abdominal Emergencies
Corresponding Author: Dr. Asha Jose V.,

Department of General Surgery, Malabar Medical College, Modakkalloor, Kozhikode,

Kerala, India.

E-mail:dr.ashajosev@gmail.com

DOI: $10.14260 /$ jemds/2022/39

How to Cite This Article:

Jose AV. A study on outcome of adult acute intestinal obstruction in a tertiary care hospital of Kerala. J Evolution Med Dent Sci 2022;11(01):203-207, DOI: 10.14260/jemds/2022/39

Submission 13-01-2022,

Peer Review 18-01-2022,

Acceptance 27-01-2022,

Published 29-01-2022.

Copyright (c) 2022 Asha Jose $V$ et al. This is an open access article distributed under Creative Commons Attribution License [Attribution 4.0 International (CC BY 4.0)] 


\section{BACKGROUND}

Among the adults Acute intestinal obstruction remains one of the commonest cause for admissions in the Emergency Department.1,2 Lots of progress has taken place in understanding the pathophysiology of small bowel obstruction since two decades and also in its diagnostic criteria and surgical management. ${ }^{3}$ In spite of which the mortality rate remains high in AAIO. ${ }^{4}$ Among the surgeons all over the world there remains a certain disagreement in the diagnostic modalities to be used and surgical intervention to be undertaken which does not seem to be the cause for high mortality rate in AAIO patients. ${ }^{5}$ Review of literature showed that nearly $20 \%$ of the surgical emergencies are due to AAIO and among hem $80 \%$ of patients with small bowel obstruction. ${ }^{6}$ The cause for obstruction in the large bowel is largely due to malignancy. ${ }^{7}$ AAIO clinically presents vomiting, abdominal pain, distension, and gross constipation. ${ }^{8}$ These symptoms differ based on the site of obstruction in the bowel. ${ }^{9}$ The key diagnostic methods in AAIO included ultrasonography, Plain X-ray and CT scan abdomen all over the world which contributed to accurate diagnosis in 60 to 70 $\%$ of the patients. ${ }^{10}$ Surgical management of AAIO is based mainly on the timely clinical identification, meticulous care to treat fluid and electrolyte imbalance, by understanding the pathophysiology ${ }^{11}$ followed by timely surgical intervention. Failure to diagnose early, delayed treatment leads to lethal results in AAIO. 12

\section{METHODS}

57 patients who underwent emergency abdominal exploration surgery for the diagnosis of AAIO were included in this study. After taking institutional ethics committee clearance the study was undertaken after obtaining patients consent.

\section{Inclusion Criteria}

1. Patients aged above 18 years and below 67 years were included

2. Patients of both genders were included.

3. Patients who have not undergone laparotomy earlier we included.

4. Patients meeting the ASA type I and II were included.

\section{Exclusion Criteria}

1. Patients aged below 18 years and above 67 years were not included (to avoid co-morbid conditions in patients above 67 years).

2. Patients with history of earlier laparotomy were not included.

3. Patients with history of diabetes and hypertension were not included.

4. Patients with systemic collagen diseases were not included. All the patients were subjected to surgical profile investigations and screened by a chosen team of doctors comprising of a surgeon, anaesthetist and radiologist for fitness to undergo laparotomy.
Laparotomy was preceded by electrolyte and fluid management in all the patients. Radiological investigations included, X-Ray chest and abdomen in erect posture, CT abdomen. Laparotomy findings were recorded by the surgeon followed by 24 hour admission in the surgical ICU to monitor further fluid and electrolyte management was taken care of in all the patients. All the patients were followed up after discharge for one month and were thus typed as three groups: R- recovered, RC- recovered with complication and D- death.

\section{Type of Study}

A prospective analytical study

\section{Institute of Study}

Malabar Medical college Hospital, Kozhikode, Kerala.

\section{Duration of Study}

Jan. 2019 to Dec. 2021.

\section{Sample Calculation}

Formula used for infinite population

$n=\frac{Z^{2} \times P(1-p)}{\varepsilon^{2}}$

where

$\mathrm{z}$ is the $\mathrm{z}$ score

$\varepsilon$ is the margin of error- $13 \%$

$\mathrm{N}$ is the population size- infinite

$\hat{\mathrm{p}}$ is the population proportion- $50 \%$

The sample calculated was- 57

\section{Statistical Analysis}

All the data collected was analysed using standard statistical methods using SPSS 21 software. Percentages, standard deviation, $\mathrm{CHi}$ square test scores, $\mathrm{p}$ values and sensitivity test formulas were used in analyzing the data and arriving the conclusions.

\section{RESULTS}

The total number of patients attending the department of General surgery were 78345 during the study period and out which the number of emergency cases were 13678 (17.45\%). Among these, emergency surgical cases 578 (04.22 \%) patients presented with AAIO. 57 (09.86 \%) patients meeting the inclusion criteria were analysed in this study. The mean age of the overall patients was $47.30 \pm 6.74$ years with the youngest patient aged 36 years and the eldest was aged 54 years. The youngest patient among the males was aged 39 years and the eldest was aged 51 years with a mean age of $42.35 \pm 2.15$ years. Among the females the youngest patient was aged 23 years and the eldest patient was aged 40 years with a mean age of $32.75 \pm 3.10$ years. There were $21(36.84$ 
$\%)$ patients in the age group of 38 to 47 years, 14 (24.56\%) patients in the age group of 28 to 37 years and 09 (15.78\%) patients in the age group of 18 to 27 years. There were 39 males and 18 females in the group with a male to female ratio of 2.16:1 (Table 1 ).

\begin{tabular}{|ccccc|}
\hline Age Distribution & Male - 39 & Percentage & Female - 18 & Percentage \\
18 to $27-09(15.78 \%)$ & 06 & 10.52 & 03 & 05.26 \\
28 to $37-14(24.56 \%)$ & 08 & 14.03 & 06 & 10.52 \\
38 to $47-21(36.84 \%)$ & 16 & 28.07 & 05 & 08.77 \\
48 to $57-07(12.28 \%)$ & 05 & 08.77 & 02 & 03.50 \\
58 to $67-06(10.52 \%)$ & 04 & 07.01 & 02 & 03.50 \\
\hline \multicolumn{4}{|c|}{ Table 1. Showing the age and gender distribution of the } \\
& AAIO patients (n-57) & \\
\hline
\end{tabular}

Radiological investigations included plain X-ray erect abdomen, CT abdomen in all patients. The results were analyzed and tabulated in Table 2 . The sensitivity of clinical examination was found to be $54.38 \%$, sensitivity of plain Xray abdomen was $68.42 \%$ and the sensitivity of of CT scan abdomen was $92.15 \%$.

\begin{tabular}{|ccccc|}
\hline Diagnosis & Total & True Positive & False Negative & Sensitivity \\
On Clinical Examination & 57 & 31 & 26 & 54.38 \\
On Plain X-ray Abdomen & 57 & 39 & 19 & 68.42 \\
$\begin{array}{c}\text { On Plain CT scan } \\
\text { abdomen }\end{array}$ & 57 & 47 & 10 & 92.15 \\
\hline Table 2. Showing the sensitivity and specificity of CT scan \\
abdomen in the diagnosis of AAIO (n - 57)
\end{tabular}

Among the 57 patients adhesions was the commonest cause of AAIO in the study accounting to 22 / 57 (38.59\%) patients; among them males were 14 / 57 (24.56 \%) and females were 08 / 57 (14.03\%) and the male to female ratio was 1.75:1. The mean age of AAIO due to adhesions was $38.70 \pm 1.05$ years. Obstructed inguinal hernia was observed in 19 / 57 (33.33\%) of the patients; 12 / 57 (21.05\%) in males and 07 / 57 (12.28 \%) in females with a male to female ratio of 1.71:1. The mean age of AAIO due to Obstructed inguinal hernia was $47.25 \pm 2.45$ years. Tumours were the cause of AAIO in 09 / 57 (15.78\%) patients; 05 / 57 (08.77 $\%)$ in males and $04 / 57(07.01 \%)$ in females with a male to female ratio of 1.25:1. The mean age of AAIO due to Obstructed inguinal hernia was $58.50 \pm 3.10$ years. Volvulus was observed as the cause of AAIO in $03 / 57$ (05.26 \%) patients; 02 / 57 in males and $01 / 57$ in females with a male to female ratio of $2: 1$. The mean age was $21.40 \pm 1.50$ years. (Table 3). TB and Intussusception were noted in $01 / 57$ (01.75\%) patients each. Strangulated bowel was observed during surgery in $10 / 57$ (17.54\%) patients in the study. Other complications were observed in 16 / 57 (28.07\%) patients (Table 3).

\begin{tabular}{|c|c|c|c|c|c|c|}
\hline $\begin{array}{c}\text { Cause of } \\
\text { Intestinal } \\
\text { obstruction }\end{array}$ & $\mathbf{M}$ & $\mathbf{F}$ & $\begin{array}{l}\text { Mean } \\
\text { age }\end{array}$ & $\begin{array}{c}\text { Strangulated } \\
\text { bowel } \\
10\end{array}$ & $\begin{array}{c}\text { Other } \\
\text { Complications } \\
16\end{array}$ & $\begin{array}{c}\text { Death } \\
11\end{array}$ \\
\hline Adhesions-22 & 18 & 04 & $\begin{array}{l}38.70 \pm \\
1.05\end{array}$ & 04 & 05 & 04 \\
\hline $\begin{array}{l}\text { Obstructed inguinal } \\
\text { Hernia- } 19\end{array}$ & 12 & 07 & $\begin{array}{c}47.25 \pm \\
2.45\end{array}$ & 03 & 05 & 05 \\
\hline Tumours- 09 & 05 & 04 & $\begin{array}{c}58.50 \pm \\
3.10\end{array}$ & 02 & 02 & 01 \\
\hline Volvulus- 03 & 02 & 01 & $\begin{array}{c}21.40 \pm \\
1.50\end{array}$ & 00 & 02 & 00 \\
\hline TB-02 & 01 & 01 & $\begin{array}{l}39.50 \pm \\
2.25\end{array}$ & 00 & 01 & 01 \\
\hline Intussusception- 02 & 01 & 01 & $\begin{array}{c}20.35 \pm \\
3.60 \\
\end{array}$ & 01 & 01 & 00 \\
\hline
\end{tabular}

Complications observed in the study were strangulated bowel in 10 / 57 (17.54 \%) patients and other complications such as Water and electrolyte imbalance was observed in 04 / 57 (07.01\%) patients, wound infection was found in 03 / $57(05.26 \%)$ patients, Wound dehiscence in $03 / 57$ (05.26 \%) patients, peritoneal abscess in 02 / 57 (03.50 \%) patients, Shock in 02 / $57(03.50 \%)$ patients, urinary tract infection in 02 / 57 (03.50 \%), Acute renal failure in 01 / 57 (01.75\%) and deep vein thrombosis in $01 / 57$ (01.75 \%) patients. (Table 3 and 4).

\begin{tabular}{|ccc|}
\hline Complication & Number & Percentage \\
\hline Strangulated Bowel & 10 & 17.54 \\
Wound infection & 03 & 05.26 \\
Wound dehiscence & 03 & 05.26 \\
Peritoneal abscess & 02 & 03.50 \\
Urinary tract infection & 01 & 01.75 \\
Deep vein thrombosis & 01 & 01.75 \\
Water and electrolyte imbalance & 04 & 07.01 \\
Shock & 02 & 03.50 \\
\hline Table 4. Showing the different complications encountered \\
in the study (n-57) \\
\hline
\end{tabular}

All the 57 patients were treated with surgery. The factors influencing the outcome in the management of AAIO patients of the study showed that age above 50 years was more prone for mortality ( $p$ value - 0.032). Presence of strangulated bowel during surgery had grave mortality ( $p$ value -0.001 ). Presence of shock was another factor contributing to the mortality ( $\mathrm{p}$ - value - 0.021). Other factors like Gender, time lapse for laparotomy, water and electrolyte imbalance, comorbidity were not significant statistically ( $p$ value more than 0.05), (Table 5).

\begin{tabular}{|c|c|c|c|c|c|}
\hline & & $\begin{array}{c}\text { Survived } \\
37\end{array}$ & $\begin{array}{r}\text { Dead } \\
20\end{array}$ & $\begin{array}{c}\mathrm{X} 2 \\
\text { value }\end{array}$ & $\begin{array}{c}\mathbf{P} \\
\text { value }\end{array}$ \\
\hline Age & $\begin{array}{l}<50 \text { years }-46 \\
>50 \text { years }-11\end{array}$ & $\begin{array}{l}45 \\
09\end{array}$ & $\begin{array}{l}01 \\
02\end{array}$ & 4.562 & 0.032 \\
\hline Gender & $\begin{array}{c}\text { Male - } 39 \\
\text { Female - } 18\end{array}$ & $\begin{array}{l}37 \\
17\end{array}$ & $\begin{array}{l}02 \\
01\end{array}$ & 0.004 & 0.946 \\
\hline $\begin{array}{l}\text { Time lapse for } \\
\text { Laparotomy }\end{array}$ & $\begin{array}{c}\text { Within } 24 \text { Hrs - } 44 \\
\text { After } 24 \text { Hrs - } 13\end{array}$ & $\begin{array}{l}43 \\
11\end{array}$ & $\begin{array}{l}01 \\
02\end{array}$ & 3.460 & 0.062 \\
\hline $\begin{array}{c}\text { Strangulated } \\
\text { Bowel }\end{array}$ & $\begin{array}{l}\text { Present - } 10 \\
\text { Absent - } 47\end{array}$ & $\begin{array}{l}07 \\
46\end{array}$ & $\begin{array}{l}03 \\
01\end{array}$ & 9.817 & 0.001 \\
\hline $\begin{array}{l}\text { Water, Electrolyte } \\
\text { imbalance }\end{array}$ & $\begin{array}{l}\text { Present - } 21 \\
\text { Absent - } 36\end{array}$ & $\begin{array}{l}18 \\
35\end{array}$ & $\begin{array}{l}03 \\
01\end{array}$ & 2.991 & 0.100 \\
\hline Comorbidity & $\begin{array}{l}\text { Present - } 15 \\
\text { Absent - } 42\end{array}$ & $\begin{array}{l}13 \\
41\end{array}$ & $\begin{array}{l}02 \\
01\end{array}$ & 2.659 & 0.102 \\
\hline Shock & $\begin{array}{l}\text { Present - } 10 \\
\text { Absent - } 47\end{array}$ & $\begin{array}{l}08 \\
46\end{array}$ & $\begin{array}{l}01 \\
01\end{array}$ & 5.282 & 0.021 \\
\hline Table 5. Sh & $\begin{array}{r}\text { owing the Risk } \\
\text { AAIO p }\end{array}$ & ctors assc & ted $v$ & ot & \\
\hline
\end{tabular}

Recovery of patients with AAIO as an outcome after treatment and incidence of death in patients with and without complications was tested for significance using chi square statistical test and observed that the test was significant with $\mathrm{p}$ value 0.027 . (Table 6)

\begin{tabular}{|cccc|}
\hline Outcome & Number & Percentage & P value \\
\hline Recovered & 20 & 35.08 & -- \\
Recovered with complication & 26 & 45.61 & $\mathrm{X}^{2}-4.838$ \\
Death & 11 & 19.29 & 0.027 \\
\hline Table 6. Showing the outcome in $\mathbf{A A I O}$ patients in the study $(\mathrm{n}-\mathbf{5 7})$ \\
\hline
\end{tabular}

Table 6. Showing the outcome in AAIO patients in the study ( $n-57)$

\section{DISCUSSION}

Adult Acute intestinal obstruction remains one of the commonest surgical emergencies all over the world and contributes to surgical admissions resulting in variable degrees of morbidity and mortality. ${ }^{13,14}$ During the study period 78345 patients visited the Department of General surgery; emergency cases were 13678 (17.45 \%), 578 (04.22 
\%) patients presented with Adult Acute intestinal obstruction. $57(09.86 \%)$ patients out of these were analysed in this study for outcome after treatment. The peak age group was 38 to 57 years. The mean age was $47.30 \pm 6.74$ years. Among the males the mean age was $42.35 \pm 2.15$ years. Among the females the mean age was $32.75 \pm 3.10$ years. The male to female ratio was 2.16:1. Drożñdz $\mathrm{W}$ et $\mathrm{al}^{7}$ and Markogiannakis $\mathrm{H}$ et $\mathrm{al}^{8}$ reported the mean ages of 25 and 63.8 years respectively. But Arshad et al, ${ }^{15}$ reported a mean age of 41.27 years; Souvik et al ${ }^{10}$ reported 45 years which were similar to the present study. The incidence of AAIO was reported as high among the males by many authors similar to the present study. 9,10

The sensitivity of clinical examination was found to be $54.38 \%$, sensitivity of plain X-ray abdomen was $68.42 \%$ and the sensitivity of of CT scan abdomen was $92.15 \% \mathrm{~m}$ (Table 2). Review of literature showed that the accuracy of CT scan in determining the presence of obstruction was between 46 $\%-80 \% .{ }^{16}$ In the present study the common cause of AAIO was adhesions which was similar to the studies reported from the Greece and Mexico.7,12 But majority of the studies reported from India and Pakistan, the causes were hernia and TB intestine. (10, 13 and 15) In a study from Nigeria, Inguinal hernia was reported as the commonest cause of intestinal obstruction resulting in strangulation of the bowel and mortality. ${ }^{17}$ In the present study adhesions were noted during laparotomy in 22 / 57 (38.59 \%) patients, (14 / 57 in males and 08 / 57 in females). Obstructed inguinal hernia was found in 19 / 57 (33.33 \%) of the patients (males-12 and females-07). Tumours were found in 09 / 57 (15.78\%) patients (males - 05 / 57 and 04 / 57 in females). Volvulus was found in $03 / 57(05.26 \%)$ patients (males - s 02 and females - 01). TB and Intussusception were noted in $01 / 57$ $(01.75 \%)$ patients each. Strangulated bowel was observed during surgery in $10 / 57$ (17.54 \%) patients in the study.

Other complications were observed in 16 / 57 (28.07 \%) patients (Table 3). The incidence of Adhesions as the cause of intestinal obstruction has decreased in proportion over the years as reported in the literature all over the world. ${ }^{18}$ The relative decrease in the incidence may be due to improved community oriented elective hernia repair and initiation of day-case hernia surgery in most of the hospitals. Formation of adhesions may be due to peritoneal tissue reaction to trauma including mechanical, thermal, foreign body reactions, infection, radiation, or ischaemic injuries. ${ }^{6}$ Adhesions were reported commonly in females young patients, 5 but in this study it was common in males. Similarly the incidence of Volvulus in causing AAIO was found to be becoming less common and tumours were reported as the cause recently. This change may be due to changes in lifestyle and dietary pattern. TB as the cause for AAIO may occur due to intraluminal strictures formation, external compression, bowel wall adhesions or traction by enlarged lymph nodes. ${ }^{19}$ AAIO due to Intussusception, intra-abdominal abscesses and mesenteric vascular occlusion are reported as miscellaneous causes ( $2 \%$ to $3 \%$ of all obstructions). ${ }^{20}$ In this study 02 / 57 $(03.50 \%)$ patients developed AAIO due to intussusception.

Early clinical diagnosis of these miscellaneous causes resulting in AAIO are usually missed because the abdominal pain, nausea or vomiting which are primary symptoms do not occur and likely to be managed conservatively. ${ }^{21}$ Ideal treatment of AAIO depends on accurate and quick diagnosis depending upon clinical features, radiological confirmation to determine the level of obstruction, predicting the outcome and provide therapeutic guidelines. ${ }^{1}$ Rapid fluid and electrolytes imbalance develops in patients with early onset of bilious vomiting, frequent attacks of colicky abdominal pain, vigorous peristalsis and less abdominal distension are frequently seen in proximal obstruction; which requires an aggressive resuscitation. ${ }^{4}$ Surgical intervention was required in all the patients $(100 \%)$ in this study with complete obstruction or bowel strangulation. Clearing the adhesions was the most frequent procedure; single stage bowel resection and primary anastomosis was undertaken in patients with strangulated bowel and gangrenous bowel segments. In a similar study by Yassaie 0 , Thompson-Fawcett M, Rossaak J. et al similar procedure resulted in low recurrence rate with significant economic benefits over other methods in patients with colonic Volvulus in most of our patients. ${ }^{22}$

Patients with TB aetiology were treated with segmental resection, repair of the stricture supplemented by tissue biopsy and antituberculous treatment. In patients with tumours as the cause of AAIO primary resection without manual reduction of intussusception was undertaken as there was possibility for co-existing malignant disease. In the present study 16 / 57 (28.07 \%) patients developed complications in this study which included: Water and electrolyte imbalance in 04 / 57 (07.01\%), wound infection in 03 / 57 (05.26\%), Wound dehiscence in 03 / 57 (05.26\%), peritoneal abscess in $02 / 57$ (03.50\%), Shock in $02 / 57$ $(03.50 \%)$, urinary tract infection in $02 / 57(03.50 \%)$, Acute renal failure in $01 / 57$ (01.75 \%) and deep vein thrombosis in $01 / 57$ (01.75 \%) patients.

A similar study by e.o ojo, C.H Ihezue et $\mathrm{al}^{23}$ a high morbidity was noted in patients with intestinal obstruction which was $29 \%$. Wound and septic complications were the most common in their study. 12 patients from their study died $(05.5 \%)$. In other reports mortality rate varied from $01.5 \%$ to $14 \%{ }^{11,24}$ In the present study the mortality noted was $19.29 \%$. The final outcome of AAIO depends not only on the causes but also on the different factors such as age, gender, time lapse to undertake laparotomy, presence of strangulated bowel segment, comorbidity, shock and water and electrolyte imbalance. Hence early identification of prognostic indicators of survival in the patients was important in guiding future therapeutic decisions and maximizing outcomes.

\section{CONCLUSIONS}

The major cause for AAIO was adhesions followed by obstructed inguinal hernias and tumours. The change in the causative factor similar to the western literature was observed. Presence of strangulated bowel during surgery had grave mortality ( $p$ value - 0.001). Presence of shock was another factor contributing to the mortality ( $p$ - value 0.021).

Data sharing statement provided by the authors is available with the full text of this article at jemds.com.

Financial or other competing interests: None. 
Disclosure forms provided by the authors are available with the full text of this article at jemds.com.

\section{REFERENCES}

[1] Wilson MS, Ellis H, Menzies D, et al. A review of the management of small bowel obstruction. Members of the Surgical and Clinical Adhesions Research Study (SCAR). Ann R Coll Surg Engl 1999;81(5):320-8.

[2] Kapan M, Onder A, Polat S, et al. Mechanical bowel obstruction and related risk factors on morbidity and mortality. Journal of Current Surgery 2012;2(2):55-61.

[3] Akigun Y, Yilmaz G, Akbayin H. Causes and effective factors on mortality of intestinal obstruction in the south east Anatolia. Turk J Med Sci 2002;32(2):149-54.

[4] Whang EE, Ashley SW, Zinner MJ. Small bowel obstruction. In: Brunicardi FC, ed. Schwartz's principles of surgery. $8^{\text {th }}$ edn. The McGraw-hill Companies Inc 2005:1027-31.

[5] Margenthaler JA, Longo WE, Virgo KS, et al. Risk factors for adverse outcomes following surgery for small bowel obstruction. Ann Surg 2006;243(4):456-64.

[6] Ergul E, Korukluoglu B. Peritoneal adhesions: facing the enemy. Int J Surg 2008;6(3):253-60.

[7] Drożñdz W, Budzyn P. Change in Mechanical bowel obstruction demographic and etiological patterns during the past century-observations from one health care institution. Arch Surg 2012;147(2):175-80.

[8] Markogiannakis H, Messaris E, Dardamanis D, et al. Acute mechanical bowel obstruction: clinical presentation, etiology, management and outcome. World J Gastroenterol 2007;13(3):432-7.

[9] Malik AM, Shah M, Pathan R, et al. Pattern of acute intestinal obstruction: is there a change in the underlying etiology? Saudi J Gastroenterol 2010;16(4):272-4.

[10] Souvik A, Hossein MZ, Amitabha D, et al. Etiology and outcome of acute intestinal obstruction: a review of 367 patients in eastern India. Saudi J Gastroenterol 2010;16(4):285-7.

[11] Lawal 00, Olayinka OS, Bankole JO. Spectrum of causes of intestinal obstruction in adult Nigerian patients. SAJS 2005;43(2):34-6.
[12] De la Garza-Villasenor L. Eatiology of intestinal occlusion. Rev Gastroenterol Mex 2001;66(4):193-6.

[13] Hadi A, Aman Z, Batool I, et al. Causes of mechanical intestinal obstruction in adults. JPMI 2010;24(3):212-6.

[14] Khan TS, Wani ML, Wani SN, et al. Clinico-pathological profile and management of acute mechanical small bowel obstruction: a prospective study. Arch Clin Exp Surg 2013;2(3):154-60.

[15] Ali A, Shah M, Pathan R, et al. Pattern of acute intestinal obstruction: is there a change in the underlying etiology? Saudi J Gastroenterol 2010;16(4):272-4.

[16] Herlinger H, Rubesin SE, Morris JB. Small bowel obstruction. In: Gore RM, Levine MS, eds. Textbook of gastrointestinal radiology. $2^{\text {nd }}$ edn. Philadelphia, $\mathrm{Pa}$ : Saunders 2000;815-37.

[17] Mabula JB, Chalya PL. Surgical management of inguinal hernias at Bugando Medical Centre in northwestern Tanzania: our experiences in a resource-limited setting. BMC Research Notes 2012;5:585.

[18] Kingsnorth AN, LeBlanc KA. Management of abdominal hernias. $3^{\text {rd }}$ ed. London, New York: Edward Arnold 2003:40-7.

[19] Sharma MP, Bhatia V. Abdominal tuberculosis. Indian J Med Res 2004;120:305-15.

[20] Naraynsingh V, Raju GC. Adult intussusception in Trinidad. Journal of the Royal College of Surgeons of Edinburgh 1987;32(1):22-3.

[21] Schein M, Sajja SBS. Early Postoperative small bowel obstruction. Br J Surg 2004;91(6):683-91.

[22] Yassaie 0, Thompson-Fawcett M, Rossaak J. Management of sigmoid volvulus: is early surgery justifiable? ANZ J Surg 2013;83(1-2):74-8.

[23] Ojo EO, Ihezue $\mathrm{CH}$, Sule AZ, et al. Aetiology, clinical pattern and outcome of adult intestinal obstruction in jos, north central Nigeria. Afr J Med Sci 2014;43(Suppl 1):29-36.

[24] Akcakaya A, Sahin M, Coskun A, et al. Comparison of mechanical bowel obstruction cases of intra-abdominal tumor and non-tumoral origin. World J Surg 2006;30(7):1295-9. 